\title{
Rehabilitation the Irrigation Canals at End Reaches
}

\author{
Soha M. Mostafa ${ }^{1}$, Gamal M. El-Shorpagy ${ }^{2}$, Magdy H. Mowafy ${ }^{2}$, Walaa Y. El- \\ Nashar $^{2}$ \\ ${ }^{I}$ (Technical office of General Administration of WR\&I for El-Sharkia Governorate, Ministry of water Resources \\ and Irrigation, Zagazig, Egypt) \\ ${ }_{2}^{2}$ (Water Engineering and Water Structure Engineering Department, Faculty of Engineering, Zagazig University, \\ Egypt)
}

\begin{abstract}
The present study covers the area in the north of El-Sharkia governorate. This area is known to be suffered from irrigation problems and the farmers always complain about irrigation issues. Irrigation networks often are seen to perform below the expectation level, requiring their rehabilitation. Unfortunately, rehabilitation works are taken up on a piece-meal basis. The main object for rehabilitation is to improve conveyance efficiency, reliability and durability of the system so as to provide irrigation water to the beneficiaries in a more sustainable and equitable manner. The objectives of this study are to study the causes for water shortage in canals tails, perform rehabilitation for sections to improve the hydraulic performance. Questionnaires for both engineers and beneficiaries approved many reasons including need for rehabilitation behind the inefficiency of irrigation canals performance. A computer program is used to choose the best solution to achieve water balance. The CCHE-GUI 3.29 program is used to run upon a case study (El-Bateekh canal), which approved the inefficiency of the canal to deliver the required discharges, while rehabilitation of the canal and remodeling the canal both improved conveyance efficiency for the same discharge.
\end{abstract}

Key Words: Canal Ends; CCHE-GUI 3.29 program; Egypt; Irrigation; Rehabilitation;

\section{Introduction}

Irrigation networks often are seen to perform below the expectation level, requiring their rehabilitation. Rehabilitation is a process of improving resources (labor, water, economic and/or environmental) utilization by upgrading the hardware and software in irrigation projects. Irrigation rehabilitation is often misunderstood as exclusively resorting to physical changes and automation, while the integrated role of hardware and software rehabilitation is not considered properly. There are a lot of researches about this topic such as Clemmens [1] measured some management, such as extending the limited rate arranged delivery schedule. Al-Jayyousi [2] presented the methodology and lessons learned from efforts to improve efficiency in the irrigation distribution system of Jericho City. Faci et al. [3] analyzed irrigation management in the irrigation district using district water, to diagnose the actual level of water management and to provide data for the modernization of the irrigation district. Playa et al. [4] developed and applied a methodology for studying modernization scenarios in an irrigation district, to establish the current performance level prior to the definition of any rehabilitation scenario. Renault [5] examined how a re-engineering approach can beneath irrigation management and canal operations and, hence, how the current, acute challenges to water management. Snell [6] discussed ideas for lining such existing canals, and some field trials that were conducted on mature sand-bed canals in Pakistan. Howarth and Lal [7] were planned a project which was implemented over a 10-year period, and was adapted throughout this time as farmer requirements and aspirations were better expressed and understood. Molden, Burton and Bos [8] provided a basic conceptual framework for the use of performance assessment in support of irrigation service. Ararso et al. [9] concluded a widespread study on water management there with two relevant statements: "it is impossible to feed the fast-growing population with improving living conditions" and "food security is achievable with the existing resources in 2025 ". Froehlich [10] analyzed the solutions to obtain the generalized trapezoidal section in the shape of sharp-cornered trapezoids, rectangles, triangles, and semicircles. Solutions presented will be useful for evaluating standard cross-sectional shapes used for lined canals in India. Adhikari, Verhoeven and Troch [11] studied primary canals of three traditional irrigation systems in the southern plains of Nepal. They offered a scientific interpretation of the indigenous technology applied to the systems, which facilitates to use the same channel network for irrigation, drainage and flood management. Karaa, Karam and Raad [12] described the measures taken by the Lebanese government in the framework of water management at the national level and to provide some recommendations in order to draw up an appropriate policy. Lecina et al. [13] analyzed the effects of irrigation modernization on water conservation, using a conceptual approach, based on water accounting and water productivity. Mateos et al. [14] presented a comprehensive analysis of the benefits and drawbacks of rehabilitation of the irrigation scheme, as a representative small-holder, community managed irrigation scheme in Mauritania, and to link this assessment to 
a general discussion on rehabilitation and design concepts. Bouisse, Baume and Gassama [15] presented the transient simulation which proved to be the only method that took into account the absorption capacity of the system which was a result of diurnal irrigation and significant storage in the distribution network. Shakir and Maqbool [16] reviewed the problems being faced by the Upper Chenab Canal and reports on the existing conditions assessed during various site visits. Morgado et al. [17] prompted the work by the lack of data on the durability of linings exposed to field conditions, and tried to fill that gap. They aimed to be a reference for future rehabilitation works and the construction of new canals and to help with more exhaustive surveys. Consoli et al. [18] imposed deficit irrigation strategies on a young orange orchard in Sicily (Southern Italy) with the aim to monitor and analyzed crop physiological features, first yield and fruit quality data for possible negative effects.

The main objective of this study is studying the causes of water shortage in canals tails, performing the rehabilitation for sections to improve the hydraulic performance and using a computer program to choose the best solution to achieve water balance for El-Bateekh canal as a case study.

\section{Study Area}

The study area is in the north of El-Sharkia governorate which includes areas of Kafr-Sakr, Awlad-Sakr, Elhosyniah, north of Abu Hammad and Faqous. This area lies between N $31^{\circ} 6^{\prime}$ and N $30^{\circ} 42^{\prime}, \quad$ E $31^{\circ} 39^{\prime}$ and E $32^{\circ} 9^{\prime}$. The area with the bold border in the map shows the study area of this research as shown in Fig 1 .

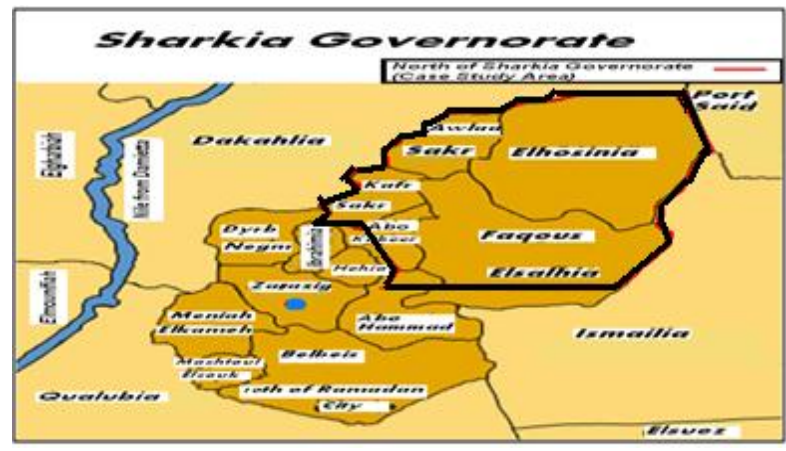

Fig 1. The East Delta Area

The Methodology of this paper is:

III. Methodology

1- Inventory of water resources in the north of El-Sharkia.

2- Collect data of canals and identify the sections that have problems of water shortage in canals tails.

3- A questionnaire is done in the area of research to identify the problem from the point of view of both beneficiaries and engineers.

4- Study the causes of water shortage in canals tails.

5- Use a computer program (CCHE-GUI 3.29) to achieve water balance for El-Bateekh canal as a case study.

\section{Data Collection}

The total numbers of branch canals in the study area are 226 canals and the area served is about $33 \%$ of the total served area in El-Sharkia governorate. The average demand for El-Sharkia is 4825 million $\mathrm{m}^{3}$ /year while as the north of El-Sharkia -area of this research- has about 35- $40 \%$ of this totals discharge. The number of canals having irrigation problems constituted about $40 \%$ of the total number of canals in area of research. The canal rotation which is used in El-Sharkia is in winter, 3 Turns with 5 days open and 10 closures, in summer 2 turns for rice areas with 5 open days and 5 days closures and 3 turns for other areas.

\section{The Questionnaire}

A questionnaire is done in the area of this research to identify the problem from the point of view of both beneficiaries and engineers. The questionnaire is divides into 5 main sections as followed: (a) management and operation; (b) maintenance; (c) discharge; (d) water structures and infrastructure; (e) suggestions.

\subsection{Engineers Questionnaires}

The questionnaire is conducted among 26 engineers whom experienced area of research and have known the nature of the area and its problems. 


\section{2 . Farmers Questionnaires}

The questionnaire is conducted among 76 farmers living in the area of this research and had known the nature of the area and its problems.

\subsection{Discussion of Questionnaires}

1- Both engineers and beneficiaries agreed that they need to increase the level of cooperation between them ( $96 \%$ for both of them).

2- Regarding the reasons for poor performance especially during summer season the opinions varied between engineers and beneficiaries. Engineers think that unauthorized crops plantation is the main reason $(66 \%)$ while beneficiaries think that the main reasons are inadequate rotation (49\%). But they both agree that all the reasons are combined (inadequate rotation, mismanagement, inadequate maintenance, unauthorized crops plantation) is the main reason ( $83 \%$ engineers, $42 \%$ of beneficiaries).

3- Only $1 \%$ of beneficiaries think that discharge is sufficient during last year while $38 \%$ of engineers think it is sufficient.

4- For mixing and lifting pump station the opinions are almost similar $46 \%$ of engineers and $41 \%$ of beneficiaries think that their capacities are sufficient.

5- Both engineers and beneficiaries agree that there is collapses along troubled canals ( $92 \%$ of engineers, $91 \%$ of beneficiaries). And they agree that there is need for lining some sections (92\% of engineers, $89 \%$ of beneficiaries).

6- Most of the factors suggest for improving performance have partially high percentage.

7- Engineers think that all factors should be improved specially rehabilitation of canals (81\%), increasing cooperation with farmers (73\%), use pump station (71\%), and increase discharge (69\%).

8- The beneficiaries think that the most important factors are increasing cooperation with irrigation districts (79\%), improve maintenance (75\%), increase discharge (67\%), and use pump station (53\%) while only $(39 \%)$ thought that there is need for rehabilitation of canals.

\section{Case Study}

In this research El-Bateekh canal is studied. Its area served is 4000 feddan, and its length is $8.3 \mathrm{~km}$. Actual discharge is $1.52 \mathrm{~m}^{3} / \mathrm{sec}$ while the designed discharge is $2.31 \mathrm{~m}^{3} / \mathrm{sec}$. Surface irrigation method is used in this canal. The map which identifies the general layout of the case study canal is shown in Fig 2.

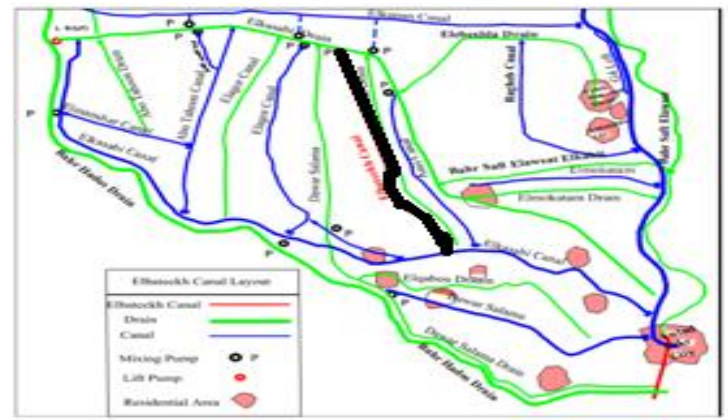

Fig 2. General Layout of El-Bateekh Canal

\subsection{The Designed and Actual Synoptic of El-Bateekh Canal}

The designed cross-sections and actual cross-sections of El-Bateekh canal at km 0.0, km 4.0, km 6.0 and $\mathrm{km} 8.0$ are shown in Fig 3.

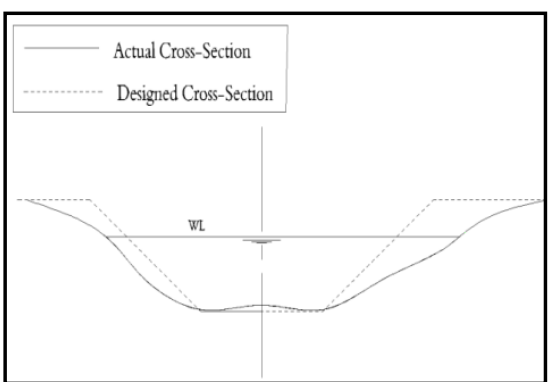

(a) at km 0.0

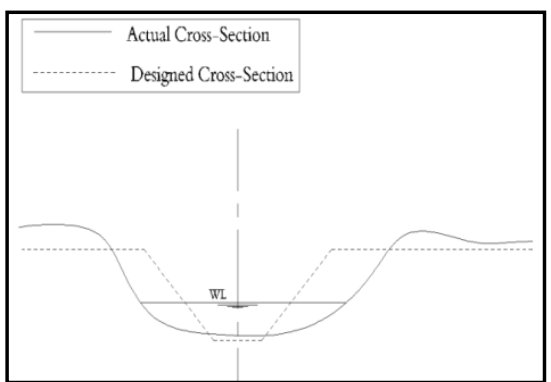

(c) at $\mathrm{km} 6.0$ 


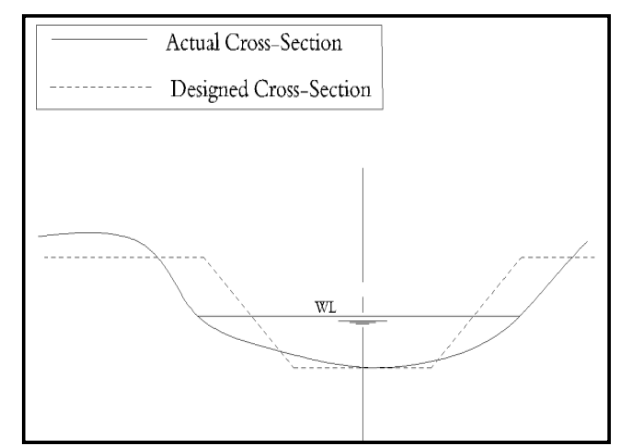

(b) at $\mathrm{km} 4.0$

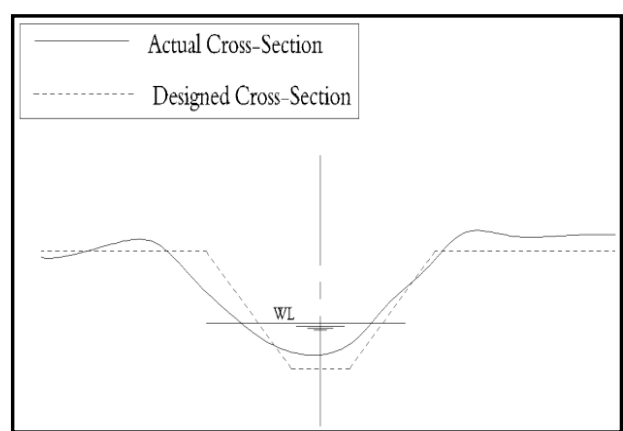

(d) at $\mathrm{km} 8.0$

Fig 3. Cross Section of El-Bateekh Canal

VII. Model Program

Center for Computational Hydro-science and Engineering (CCHE-GUI 3.29) program is used in this research. (CCHE-GUI 3.29) is consisted of two programs:

1- CCHE-MESH: 2D Structured Mesh Generator -Version 3.x;

2- CCHE-GUI - Graphical Users Interface for NCCHE Model - Version 3.0;

The numerical modeling based on solving the Navier-Stokes equations is an initial-boundary value problem. Users must provide initial conditions and the boundary conditions. The general procedure of a numerical simulation can be simply listed as follows:

- Mesh generation;

- Specification of boundary condition;

- Parameters setting;

- Simulation;

-Results of visualization and interpretation.

\section{Application Of The Model}

In this research, El-Bateeekh canal is taken as a case study. Flow and sedimentation analysis are done for different cross sections of El-Bateekh canal for six cases:

1- First run (area actual, Q actual)

2-Second run (area actual, Q actual+ lift pump);

3-Third run (area designed, Q designed);

4-Fourth run (area designed, Q actual + lift pump);

5- Fifth run (new area designed, Q designed (suggested new designed case));

6- Sixth run (new area designed, Q actual + pump (suggested new designed Case).

The resulted of velocities magnitudes and sedimentation (bed changes) for the sections at $(0 \mathrm{~km}, 2 \mathrm{~km}, 4 \mathrm{~km}$, $6 \mathrm{~km}, 8 \mathrm{~km}$ and $8.3 \mathrm{~km}$ ) of El-Bateekh canal are calculated by the program for each case.

\section{1. ${ }^{\text {st }}$ Run: Area actual and $Q_{\text {actual }}$}

\section{Results Of The Program}

In this run the actual discharge, water levels and cross-sections are entered and the resulted velocities magnitudes along the canal. The sediment initial conditions and sediment parameters are entered and the resulted of velocity magnitude and bed changes along the canal are shown in Fig 4.

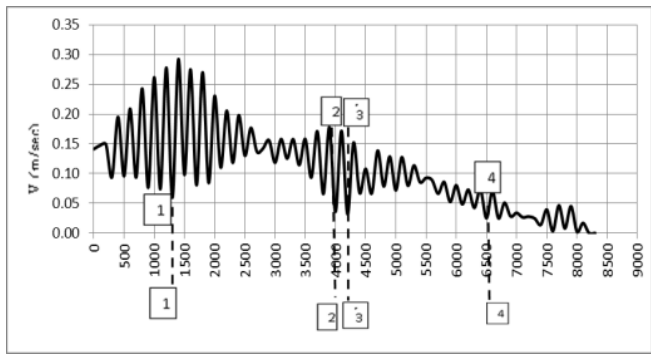

(a) Velocity Magnitude along Canal

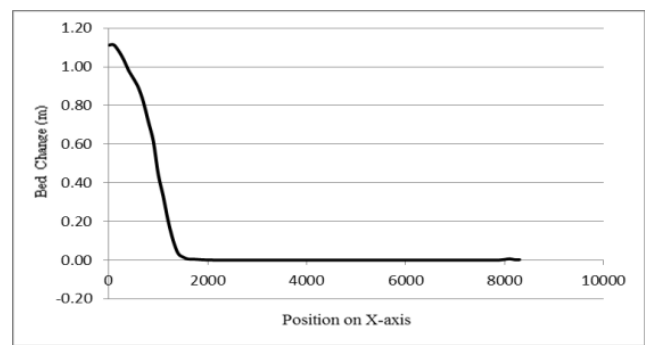

(b) Bed Changes along Canal

Fig 4. Results of Case1 


\section{2. $2^{\text {nd }}$ Run: Area actual, $Q_{\text {actual }}+$ Lift pump (Actual Case)}

The resulted of velocities magnitude along the canal and bed changes are shown in Fig 5 .

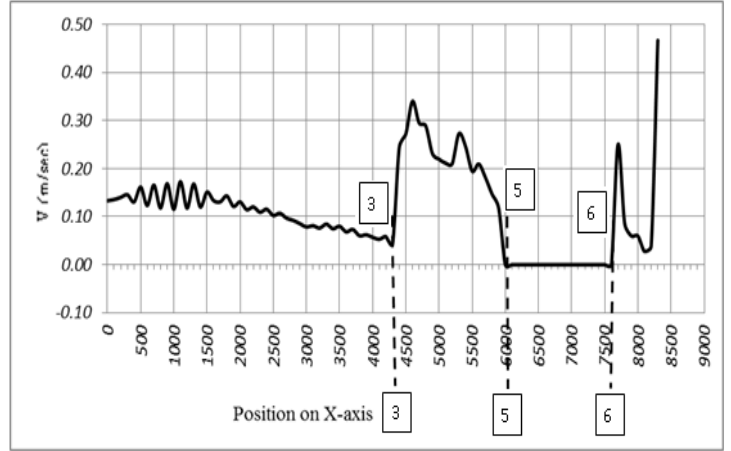

(a) Velocity Magnitude along Canal

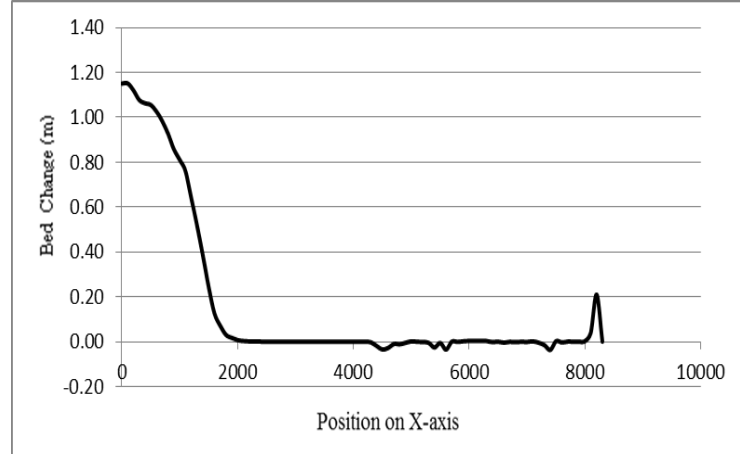

(b) Bed Changes along Canal

Fig 5. Results of Case2

9.3. $3^{\text {rd }}$ Run: Area designed, $Q_{\text {designed }}$ (Designed Case)

The resulted of velocities magnitude and bed changes along the canal are shown in Fig 6.

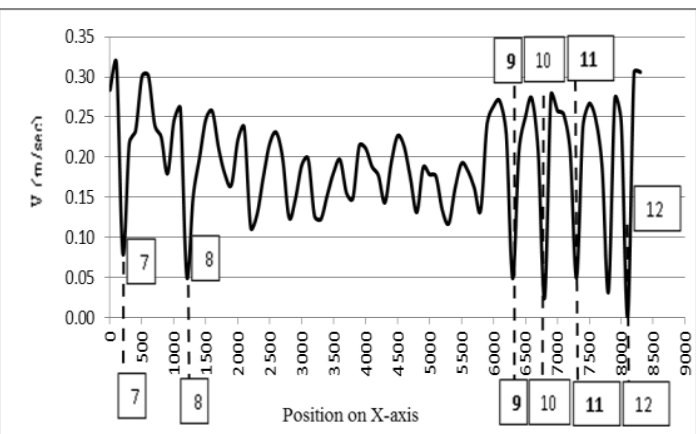

(a) Velocity Magnitude along Canal

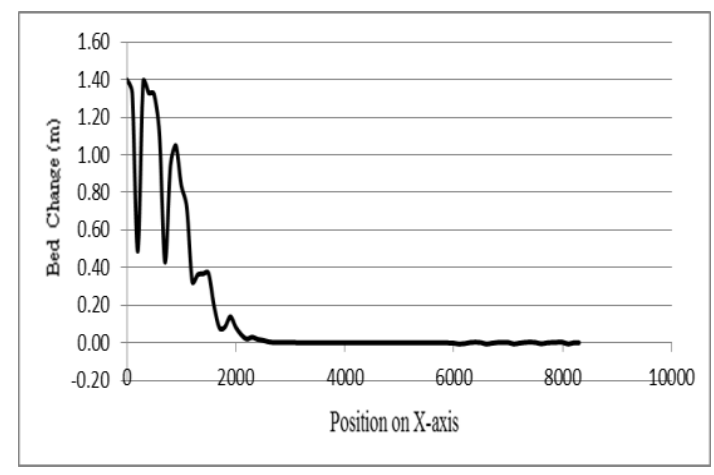

(b) Bed Changes along Canal

Fig 6. Results of Case 3

\section{4. $4^{\text {th }}$ Run, Area Designed, $Q_{\text {actual }}+$ Lift pump}

The resulted of velocities magnitude and bed changes along the canal are shown in Fig 7.

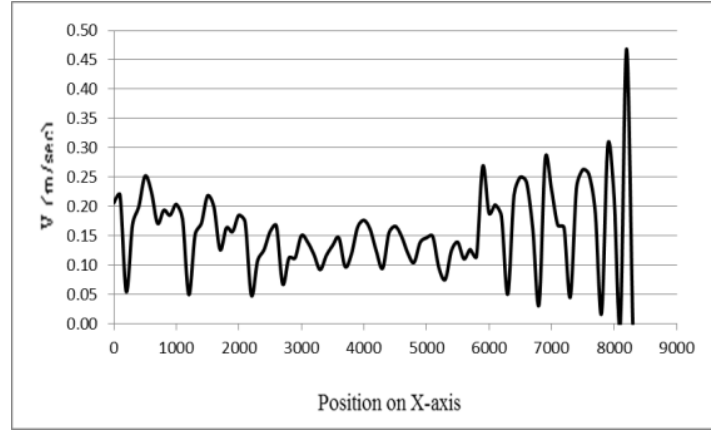

(a) Velocity Magnitude along Canal

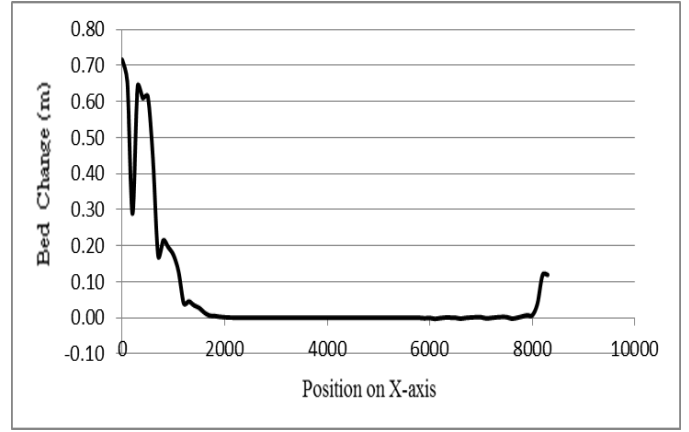

(b) Bed Changes along Canal

Fig 7. Results of Case4 


\section{5. $5^{\text {th }}$ Run, New Area Designed, $Q_{\text {designed }}$ (Suggested New Designed Case)}

The resulted of velocities magnitude and bed changes along the canal are shown in Fig 8 .

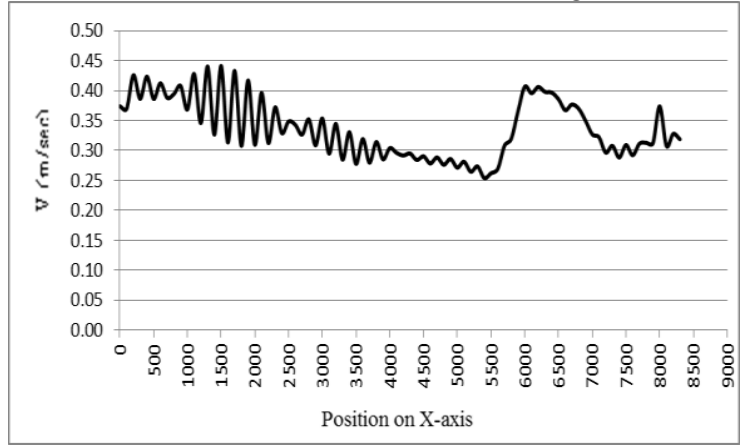

(a) Velocity Magnitude along Canal

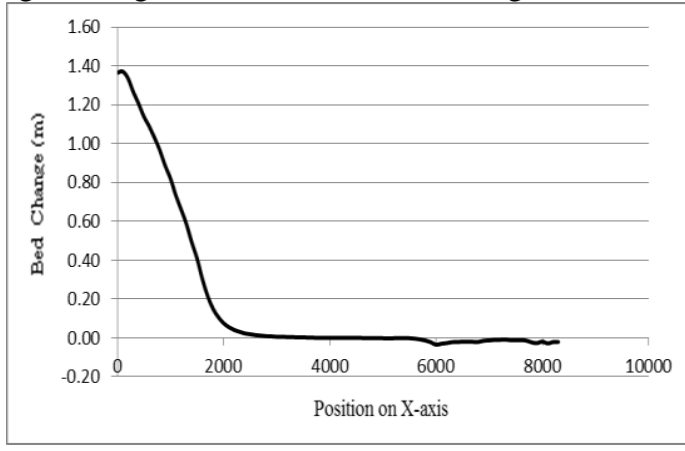

(b) Bed Changes along Canal

Fig 8. Results of Case5

9.6. $6^{\text {th }}$ Run: New Area designed, $Q_{\text {actual }}+$ Pump (Suggested New Designed Case)

The resulted velocities of magnitude and bed changes along the canal are shown in Fig 9.

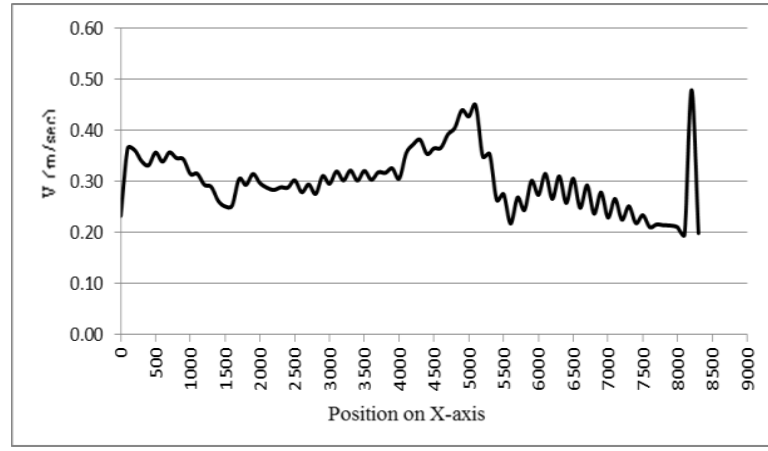

(a) Velocity Magnitude along Canal

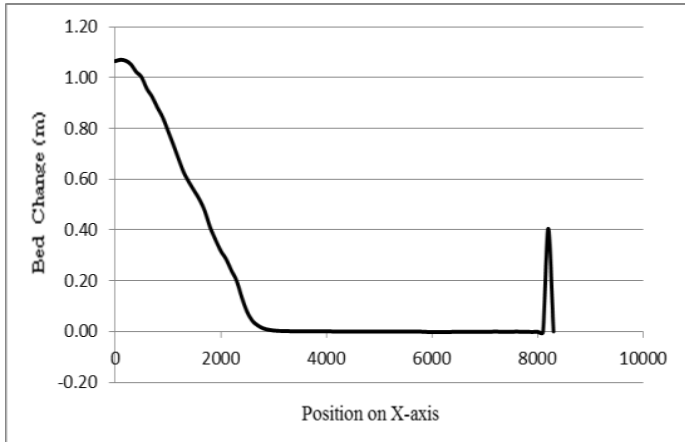

(b) Bed Changes along Canal

Fig 9. Results of Case 6

\section{Discussion Of The Results}

The critical sections marked in the previous sections and bed changes will be discussed. First, a comparison of velocities of theses sections resulted from different run cases (case of actual discharge plus lift pump, case of actual discharge, case of designed discharge calculated with respect to area served and designed cross-section, and case of designed discharge calculated with respect to area served and suggested new designed cross-section). Second, the bed level change is discussed in different section.

\subsection{Comparison of Velocities for Critical Sections}

The lowest velocities resulted from the actual discharge case and actual cross-section is shown in Fig 10, the velocities are high value in case of designed cross-section and case of suggested new designed cross section. This proved that using smaller cross-section area for case of decreasing discharges (as in the actual case) will resulted in higher velocities and better performance of canal.

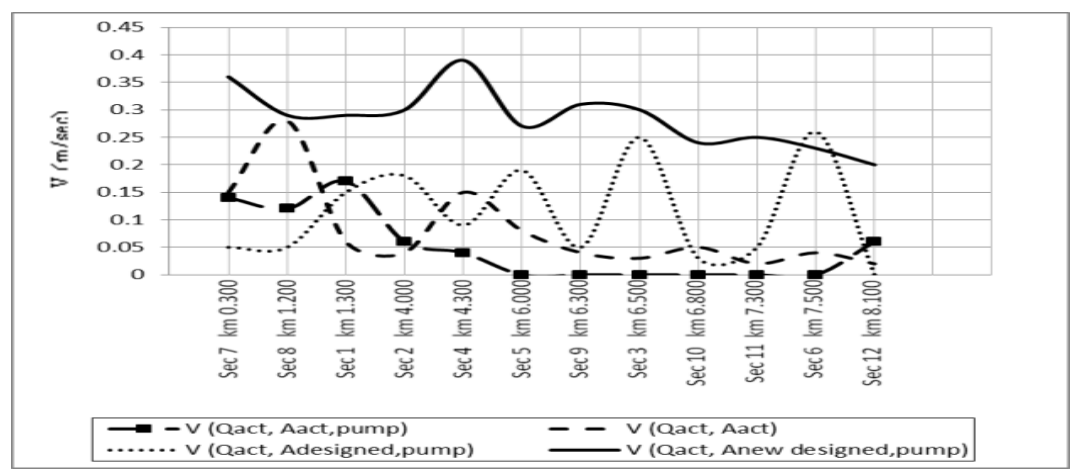

Fig 10. Velocity Magnitude of Critical Sections for Different Run Cases 


\subsection{Discussion of Bed Level Change and Velocity Magnitude}

\subsubsection{Section 1-1, at $\mathrm{km} 1.30$}

There is obvious change in the shape of the cross section of the canal as shown in Fig 11, the actual cross section area is $11.71 \mathrm{~m}^{2}$ while as the designed cross section area is $9.46 \mathrm{~m}^{2}$, and the area of the suggested new designed section is $6.17 \mathrm{~m}^{2}$. The velocity of the designed cross section is $0.15 \mathrm{~m} / \mathrm{sec}$, the velocity of the actual cross section is $0.06 \mathrm{~m} / \mathrm{sec}$ and the velocity of the actual cross section (case of + pump) is $0.17 \mathrm{~m} / \mathrm{sec}$, while as the velocity will be increased to $0.29 \mathrm{~m} / \mathrm{sec}$ if we used the new suggested cross section (for the same actual discharge).

\subsubsection{Section 2-2, at $\mathrm{km} 4.0$}

There is obvious change in the shape of the cross section of the canal as shown in Fig 12, the actual cross section area is $5.97 \mathrm{~m}^{2}$ while as the designed cross section area is $4.89 \mathrm{~m}^{2}$, and the area of the suggested new designed section is $3.28 \mathrm{~m}^{2}$. The velocity of the designed cross section is $0.18 \mathrm{~m} / \mathrm{sec}$, the velocity of the actual cross section is $0.04 \mathrm{~m} / \mathrm{sec}$ and the velocity of the actual cross section (case of + pump) is $0.06 \mathrm{~m} / \mathrm{sec}$, while as the velocity will be increased to $0.3 \mathrm{~m} / \mathrm{sec}$ if we used the new suggested cross section (for the same actual discharge).

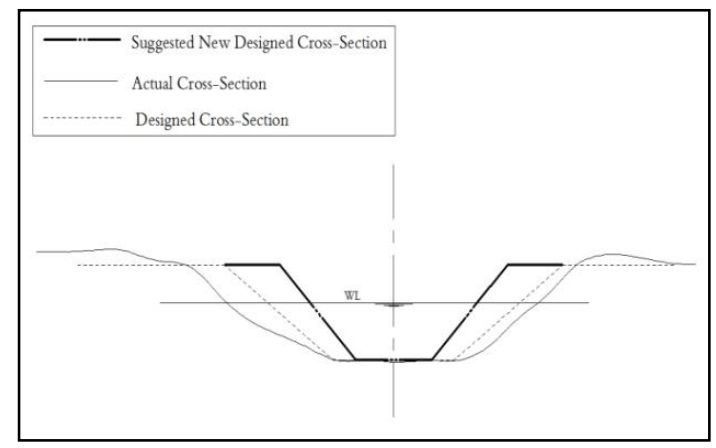

Fig 11. Cross-Sections of Section 1-1 at $\mathrm{km} 1.30$

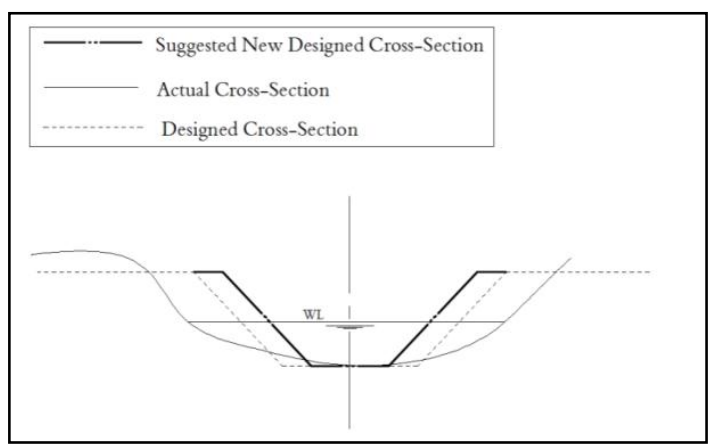

Fig 12. Cross-Section of Section 2-2 at $\mathrm{km} 4.0$

\subsubsection{Section 3-3, at km 6.50}

There is obvious change in the shape of the cross section of the canal as shown in Fig 13, the actual cross section area is $3.32 \mathrm{~m}^{2}$ while as the designed cross section area is $2.19 \mathrm{~m}^{2}$, and the area of the suggested new designed section is $1.74 \mathrm{~m}^{2}$. The velocity of the designed cross section is $0.25 \mathrm{~m} / \mathrm{sec}$, the velocity of the actual cross section is $0.03 \mathrm{~m} / \mathrm{sec}$ and the velocity of the actual cross section (case of +pump) is $0.00 \mathrm{~m} / \mathrm{sec}$, while as the velocity will be increased to $0.3 \mathrm{~m} / \mathrm{sec}$ if we used the new suggested cross section (for the same actual discharge).

\subsubsection{Section 4-4, at $\mathrm{km} 4.30$}

There is obvious change in the shape of the cross section of the canal as shown in Fig 14, the actual cross section area is $5.08 \mathrm{~m}^{2}$ while as the designed cross section area is $4.89 \mathrm{~m}^{2}$, and the area of the suggested new designed section is $3.28 \mathrm{~m}^{2}$. The velocity of the designed cross section is $0.09 \mathrm{~m} / \mathrm{sec}$, the velocity of the actual cross section is $0.15 \mathrm{~m} / \mathrm{sec}$ and the velocity of the actual cross section (case of +pump) is $0.04 \mathrm{~m} / \mathrm{sec}$, while as the velocity will be increased to $0.39 \mathrm{~m} / \mathrm{sec}$ if we used the new suggested cross section (for the same actual discharge).

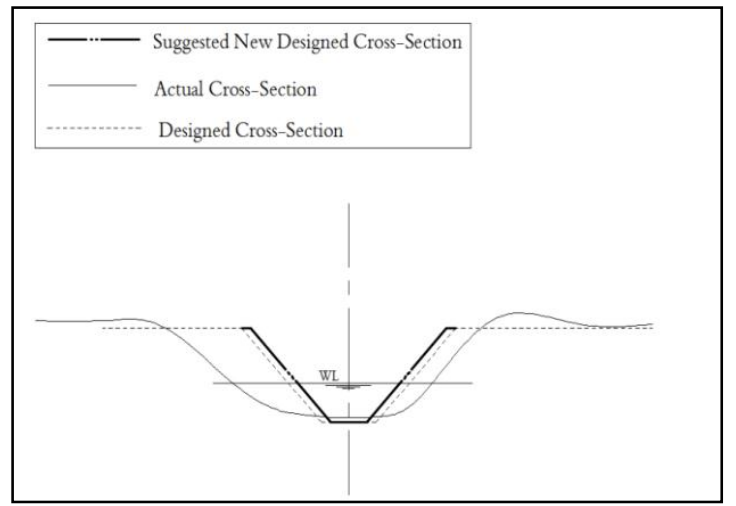

Fig 13. Cross-Section for Section 3-3 at $\mathrm{km} 6.50$

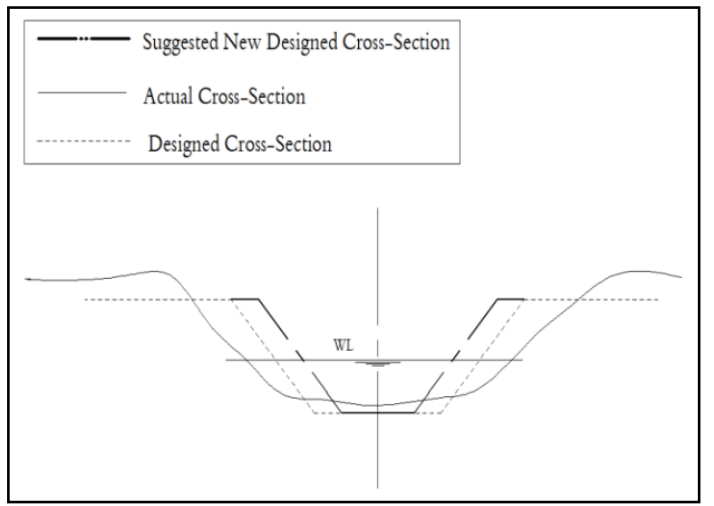

Fig 14. Cross-Section for Section 4-4 at km 4.30 


\subsubsection{Section 5-5, at $\mathrm{km} 6.0$}

There is obvious change in the shape of the cross section of the canal as shown in Fig 15, the actual cross section area is $3.88 \mathrm{~m}^{2}$ while as the designed cross section area is $2.19 \mathrm{~m}^{2}$, and the area of the suggested new designed section is $1.74 \mathrm{~m}^{2}$. The velocity of the designed cross section is $0.19 \mathrm{~m} / \mathrm{sec}$, the velocity of the actual cross section is $0.08 \mathrm{~m} / \mathrm{sec}$ and the velocity of the actual cross section (case of +pump) is $0.00 \mathrm{~m} / \mathrm{sec}$, while as the velocity will be increased to $0.27 \mathrm{~m} / \mathrm{sec}$ if we used the new suggested cross section (for the same actual discharge).

\subsubsection{Section 6-6, at $\mathrm{km} 7.50$}

There is a change in the shape of the cross section of the canal as shown in Fig 16, the actual cross section area is $1.14 \mathrm{~m}^{2}$ while as the designed cross section area is $2.00 \mathrm{~m}^{2}$, and the area of the suggested new designed section is $1.57 \mathrm{~m}^{2}$. The velocity of the designed cross section is $0.26 \mathrm{~m} / \mathrm{sec}$, the velocity of the actual cross section is $0.04 \mathrm{~m} / \mathrm{sec}$ and the velocity of the actual cross section (case of +pump) is $0.00 \mathrm{~m} / \mathrm{sec}$, while as the velocity will be increased to $0.23 \mathrm{~m} / \mathrm{sec}$ if we used the new suggested cross section (for the same actual discharge).

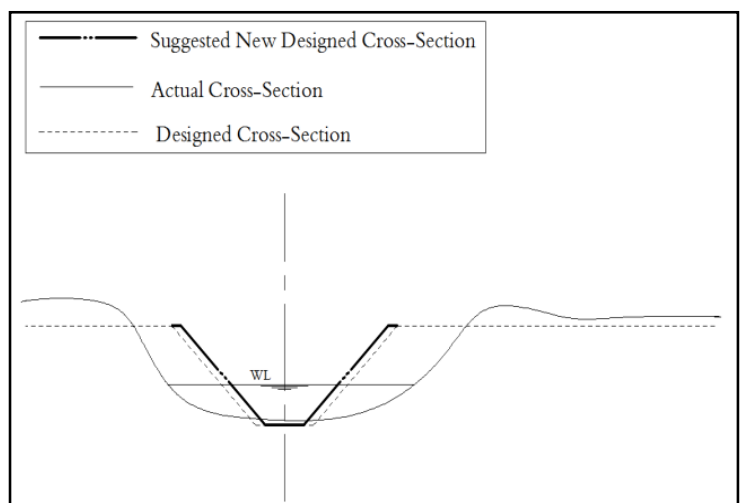

Fig 15. Cross-Section for Section 5-5 at $\mathrm{km} 6.0$

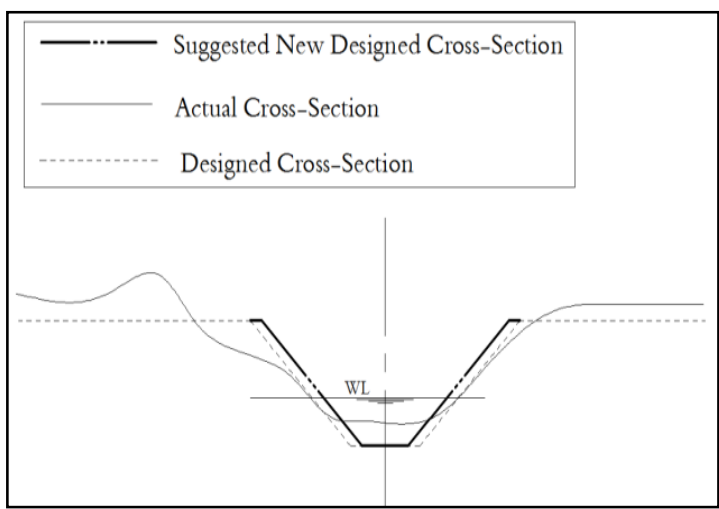

Fig 16. Cross-Section for Section 6-6 at km 7.50

\subsubsection{Section 7-7, at km 0.20}

There is obvious change in the shape of the cross section of the canal as shown in Fig 17, the actual cross section area is $14.43 \mathrm{~m}^{2}$ while as the designed cross section area is $10.93 \mathrm{~m}^{2}$, and the area of the suggested new designed section is $7.14 \mathrm{~m}^{2}$. The velocity of the designed cross section is $0.05 \mathrm{~m} / \mathrm{sec}$, the velocity of the actual cross section is $0.15 \mathrm{~m} / \mathrm{sec}$ and the velocity of the actual cross section (case of + pump) is $0.14 \mathrm{~m} / \mathrm{sec}$, while as the velocity will be increased to $0.36 \mathrm{~m} / \mathrm{sec}$ if we used the new suggested cross section (for the same actual discharge).

\subsubsection{Section 8-8, at $\mathrm{km} 1.20$}

There is obvious change in the shape of the cross section of the canal as shown in Fig 18, the actual cross section area is $12.41 \mathrm{~m}^{2}$ while as the designed cross section area is $10.93 \mathrm{~m}^{2}$, and the area of the suggested new designed section is $7.14 \mathrm{~m}^{2}$. The velocity of the designed cross section is $0.05 \mathrm{~m} / \mathrm{sec}$, the velocity of the actual cross section is $0.28 \mathrm{~m} / \mathrm{sec}$ and the velocity of the actual cross section (case of +pump) is $0.12 \mathrm{~m} / \mathrm{sec}$, while as the velocity will be increased to $0.29 \mathrm{~m} / \mathrm{sec}$ if we used the new suggested cross section (for the same actual discharge).

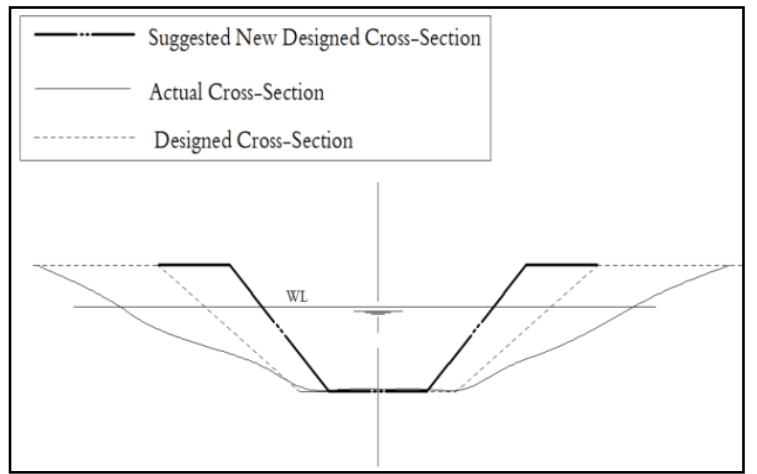

Fig 17. Cross-Section for Section 7-7 at $\mathrm{km} 0.20$

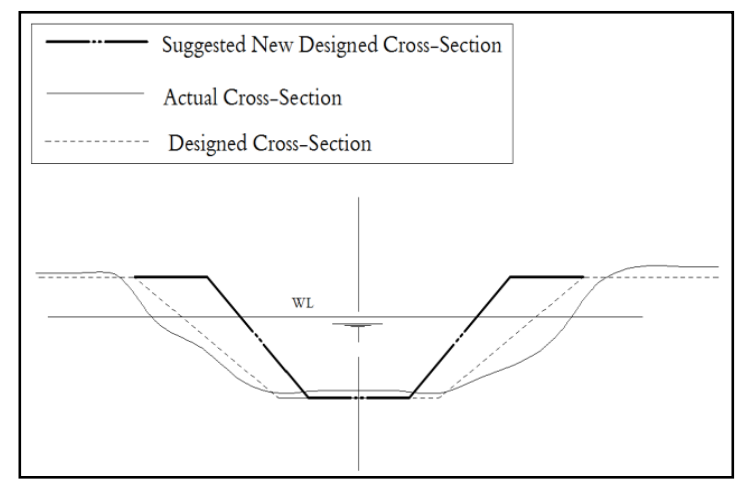

Fig 18. Cross-Section for Section 8-8 at km 1.20 


\subsubsection{Section 9-9, at $\mathrm{km} 6.30$}

There is obvious change in the shape of the cross section of the canal as shown in Fig 19, the actual cross section area is $3.67 \mathrm{~m}^{2}$ while as the designed cross section area is $2.19 \mathrm{~m}^{2}$, and the area of the suggested new designed section is $1.74 \mathrm{~m}^{2}$. The velocity of the designed cross section is $0.05 \mathrm{~m} / \mathrm{sec}$, the velocity of the actual cross section is $0.04 \mathrm{~m} / \mathrm{sec}$ and the velocity of the actual cross section (case of +pump) is $0.00 \mathrm{~m} / \mathrm{sec}$, while as the velocity will be increased to $0.31 \mathrm{~m} / \mathrm{sec}$ if we used the new suggested cross section (for the same actual discharge).

\subsubsection{Section 10-10, at $\mathrm{km} 6.80$}

There is obvious change in the shape of the cross section of the canal as shown in Fig 20, the actual cross section area is $3.14 \mathrm{~m}^{2}$ while as the designed cross section area is $2.19 \mathrm{~m}^{2}$, and the area of the suggested new designed section is $1.74 \mathrm{~m}^{2}$. The velocity of the designed cross section is $0.03 \mathrm{~m} / \mathrm{sec}$, the velocity of the actual cross section is $0.05 \mathrm{~m} / \mathrm{sec}$ and the velocity of the actual cross section (case of +pump) is $0.00 \mathrm{~m} / \mathrm{sec}$, while as the velocity will be increased to $0.24 \mathrm{~m} / \mathrm{sec}$ if we used the new suggested cross section (for the same actual discharge).

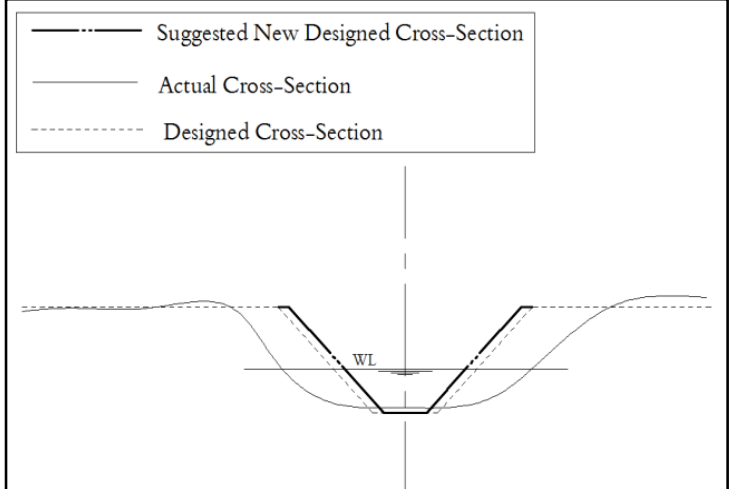

Fig 19. Cross-Section for Section 9-9 at $\mathrm{km} 6.30$

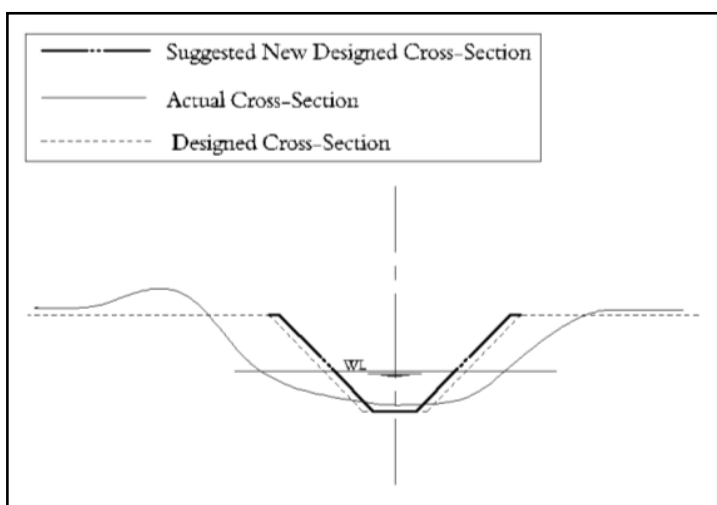

Fig 20. Cross-Section for Section 10-10 at km 6.80

\subsubsection{Section 11-11, at km 7.30}

There is a change in the shape of the cross section of the canal as shown in Fig 21, the actual cross section area is $1.19 \mathrm{~m}^{2}$ while as the designed cross section area is $2.00 \mathrm{~m}^{2}$, and the area of the suggested new designed section is $1.57 \mathrm{~m}^{2}$. The velocity of the designed cross section is $0.05 \mathrm{~m} / \mathrm{sec}$, the velocity of the actual cross section is $0.02 \mathrm{~m} / \mathrm{sec}$ and the velocity of the actual cross section (case of +pump) is $0.00 \mathrm{~m} / \mathrm{sec}$, while as the velocity will be increased to $0.25 \mathrm{~m} / \mathrm{sec}$ if we used the new suggested cross section (for the same actual discharge).

\subsubsection{Section 12-12, at km 8.10}

There is a change in the shape of the cross section of the canal as shown in Fig 22, the actual cross section area is $1.36 \mathrm{~m}^{2}$ while as the designed cross section area is $2.00 \mathrm{~m}^{2}$, and the area of the suggested new designed section is $1.57 \mathrm{~m}^{2}$. The velocity of the designed cross section is $0.00 \mathrm{~m} / \mathrm{sec}$, the velocity of the actual cross section is $0.02 \mathrm{~m} / \mathrm{sec}$ and the velocity of the actual cross section (case of +pump) is $0.06 \mathrm{~m} / \mathrm{sec}$, while as the velocity will be increased to $0.20 \mathrm{~m} / \mathrm{sec}$ if we used the new suggested cross section (for the same actual discharge).

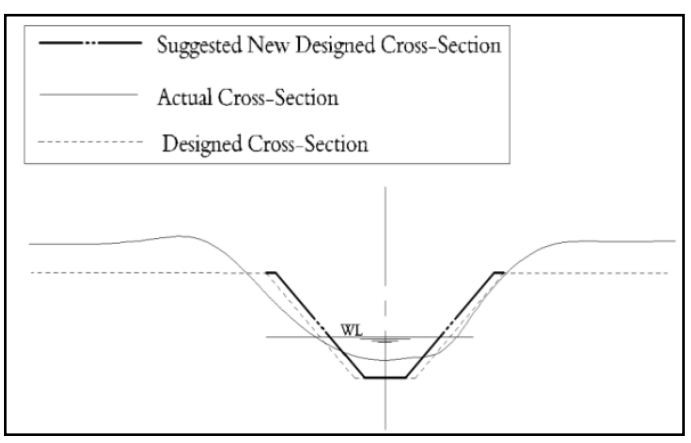

Fig 21. Cross-Section for Section 11-11 at $\mathrm{km} .30$

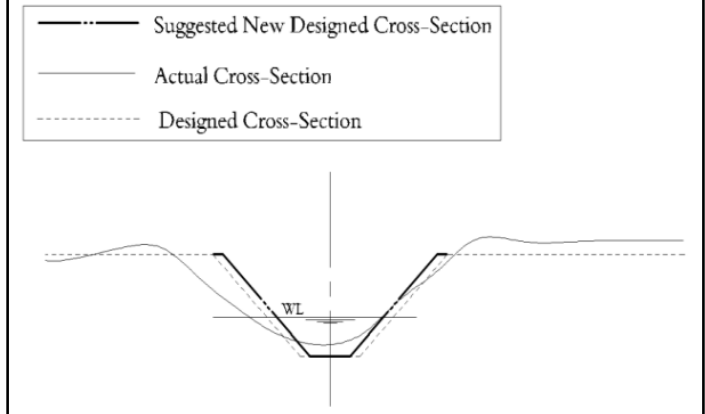

Fig 22. Cross-Section for Section 12-12 at km 8.10 


\subsection{Discussion of the Cost of Rehabilitation of El-Bateekh Canal}

1-Rehabilitation of the canal to its designed cross section will require amount of fill about $25,000 \mathrm{~m}^{3}$ and amount of digging about $4,000 \mathrm{~m}^{3}$. Assumed cost of fill $20 \mathrm{LE} / \mathrm{m}^{3}$ and cost of $3 \mathrm{LE} / \mathrm{m}^{3}$ thus the total cost will be about 500,000 LE.

2- Rehabilitation of the canal to its suggested designed cross section will require amount of fill about $50,000 \mathrm{~m}^{3}$ and amount of digging about $4,500 \mathrm{~m}^{3}$. The total cost will be about $1000000 \mathrm{LE}$.

3- Although the cost of rehabilitation to the suggested designed cross-section is higher than the cost of the rehabilitation to the original designed cross-section but other benefits must be considered as decreasing discharge and increasing velocity especially in case of water poverty Egypt might face and the need to save water consumption. Anyway, in both cases a better performance for the canal will be achieved.

4- It should be mentioned that if the fill amounts were available and transported from other places to the canal location, the cost will be reduced almost to its half.

\section{Conclusions}

Rehabilitation process in this research is applied on the north of El-Sharkia. Study the causes for water shortage in canals tails is done by a questionnaire which is done in the area of research to identify the problem from the point of view of both beneficiaries and engineers. The questionnaire was divides into 5 main sections as followed: (a) management and operation; (b) maintenance; (c) discharge; (d) water structures and infrastructure; (e) suggestions. Use a computer program (CCHE-GUI 3.29) to achieve water balance for ElBateekh canal as a case study. The velocities magnitudes and sedimentation (bed changes) for the sections at $(0 \mathrm{~km}, 2 \mathrm{~km}, 4 \mathrm{~km}, 6 \mathrm{~km}, 8 \mathrm{~km}$ and $8.3 \mathrm{~km})$ of El-Bateekh canal are calculated by this program for six cases. The cost of rehabilitation of El-Bateekh canal to achieve the best cross section is done.

\section{References}

[1] Clemmens "Delivery System Schedules and Required Capacities. In: Planning, Operation, Rehabilitation and Automation of Irrigation Water Delivery Systems" Portland, OR, USA, 1987; 18-34.

[2] Al-Jayyousi "Rehabilitation of Irrigation Distribution Systems: The Case of Jericho City" Water Resources Management, 1999; 13: 117-132.

[3] Faci, Bensaci, Slatni and Playa "A Case Study for Irrigation Modernization I. Characterization of the District and Analysis of Water Delivery Records" Agricultural Water Management 42, 2000; 313-334.

[4] Playa, Slatni, Castillo and Faci "A Case Study for Irrigation Modernization: II. Scenario Analysis" Agricultural Water Management, $2000 ; 335-354$

[5] Renault "Re-engineering Irrigation Management and System Operations" Agricultural Water Management 47, 2001; 211-226.

[6] Snell "Lining Old Irrigation Canals: Thoughts and Trials" Journal of Irrigation and Drainage, 2001; 50:139-157.

[7] Howarth and Lal "Irrigation and Participation: Rehabilitation of the Rajapur project in Nepal" Irrigation and Drainage Systems, 2002; 16: 111-138.

[8] Molden, Burton and Bos " Performance Assessment, Irrigation Service Delivery and Poverty Reduction: Benefits of Improved System Management" Journal of Irrigation and Drainage, 2007;56: 307-320.

[9] Ararso, Schultz and Hollanders "Planning Water Management for Secure Food Production in Sub-Saharan Africa" Journal of Irrigation and Drainage, 2008.

[10] Froehlich "Most Hydraulically Efficient Standard Lined Canal Sections" Journal of Irrigation and Drainage Engineering, 2008; 462470

[11] Adhikari, Verhoeven and Troch "Appropriate rehabilitation strategy for a traditional irrigation supply system: a case from the Babai area in Nepal" Water Science \& Technology-WST, 2009.

[12] Karaa, Karam and Raad, "Modernization of irrigation systems: measures to reduce pressure on water demand in Lebanon" Technological Perspectives for Rational Use of Water Resources in the Mediterranean Region, 2009.

[13] Lecina, Isidoro, Play and Aragüés "Irrigation Modernization and Water Conservation in Spain: The case of Riegos Del Alto Arag n" Agricultural Water Management 97, 2010; 1663-1675.

[14] Mateos, Lozano, Baghil, Diallo, Macpherson, Comas and Connor "Irrigation Performance before and after Rehabilitation of a Representative, Small Irrigation Scheme besides the Senegal River, Mauritania" Agricultural Water Management 97, 2010; 901909.

[15] Bouisse, Baume and Gassama"The Use of Hydraulic Models to Optimize The Rehabilitation of an Open Channel Irrigation System: The Example of the Senegal River Delta Irrigation System" Journal of Irrigation and Drainage, 2011; 60: $308-317$.

[16] Shakir and Maqbool "Remodeling of the Upper Chenab Canal: A Case Study from Pakistan" Journal of Irrigation and Drainage, 2011; 60: 285-295.

[17] Morgado, Gran, Lopes, Brito and Feiteira "Portuguese Irrigation Canals: Lining Solutions, Anomalies and Rehabilitation" Journal of Performance of Constructed Facilities, 2012; 507-515.

[18] Consoli, Stagno, Roccuzzo, Cirelli and Intrigliolo "Sustainable Management of Limited Water Resources in a Young Orange Orchard" Agricultural Water Management, 2014; 132: 60- 68. 